\title{
High intraspecific phenotypic variation, but little evidence for local adaptation in Geum reptans populations in the Central Swiss Alps
}

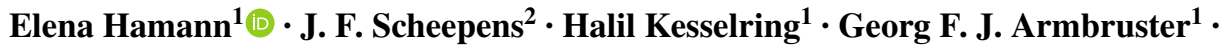 \\ Jürg Stöcklin ${ }^{1}$
}

Received: 24 September 2016 / Accepted: 13 January 2017 / Published online: 8 February 2017

(C) The Author(s) 2017. This article is published with open access at Springerlink.com

\begin{abstract}
The Alpine landscape is characterized by high spatiotemporal heterogeneity in environmental variables, such as climate and soil characteristics. This may lead to divergent selection pressures across plant populations and to local adaptation. Geum reptans, a widespread highalpine clonal herb, has been the subject of several studies investigating phenotypic variation in populations across the Swiss Alps, yet so far, there is only little knowledge about local adaptation in this species from reciprocal transplantations across original field sites. Here, we reciprocally transplanted three populations of Geum reptans in the Central Swiss Alps, growing at close or far geographical distance from each other, and compared growth- and reproductionrelated traits to investigate patterns of local adaptation. We further measured leaf morphological traits to assess potential selection at field sites, and quantified the relative importance of genetic vs. environmental variation (i.e., phenotypic plasticity) for all traits. Additionally, among and within population genetic differentiation was analyzed using microsatellite markers. Molecular diversity was high within populations, and molecular differentiation increased with geographic distance among populations, suggesting
\end{abstract}

Electronic supplementary material The online version of this article (doi:10.1007/s00035-017-0185-y) contains supplementary material, which is available to authorized users.

Elena Hamann

elena.hamann@unibas.ch

1 Department of Environmental Sciences, Section Plant Ecology, Institute of Botany, University of Basel, Schönbeinstrasse 6, 4056 Basel, Switzerland

2 Plant Evolutionary Ecology, Institute of Evolution and Ecology, University of Tübingen, Auf der Morgenstelle 5, 72076 Tübingen, Germany that gene flow is maintained at close range, but decreased with distance. Although extensive phenotypic variation was found across site $\times$ population transplant combinations, our study revealed little evidence for local adaptation in $G$. reptans populations. Plant traits also showed strong plasticity, as revealed by pronounced site effects, yet no direct linear selection was detected on leaf trait values within field sites. We suggest that the glacier forelands studied here, which are representative of the habitat of large G. reptans populations, are too similar in environmental conditions to lead to among population intraspecific differentiation in line with local adaptation. As G. reptans showed a great capacity to respond plastically to environmental conditions, we cautiously advocate that the evolution of phenotypic plasticity might have prevailed over genetic differentiation for the adaptation to the relatively narrow niche of this species.

Keywords Genetic differentiation · High-alpine clonal herb $\cdot$ Molecular variation $\cdot$ Phenotypic plasticity .

Reciprocal transplantation experiment

\section{Introduction}

Alpine ecosystems are characterized by steep environmental gradients over short geographic distances (Körner 2003) and a patchy microhabitat distribution (Scherrer and Körner 2011), which offers numerous niches to alpine plant species (Aeschimann et al. 2004). These characteristics of the alpine landscape are often also associated with spatial isolation among populations and restricted gene flow (Stöcklin et al. 2009), which may allow for intraspecific population differentiation and local adaptation. Furthermore, at high elevation, plant life is challenged by low temperatures, 
late snow-melting, short vegetation periods, and extreme weather events (Billings and Mooney 1968; Körner 2003). In this heterogeneous habitat, plants can adapt genetically to locally prevailing conditions (Byars et al. 2007; GonzaloTurpin and Hazard 2009), and/or respond to spatiotemporal variability in environmental conditions via adaptive phenotypic plasticity (Sultan 1995).

Intraspecific phenotypic variation resulting from genetic drift or natural selection (Volis et al. 2015) is common in widely distributed species (Bradshaw 1984; Joshi et al. 2001; Banta et al. 2007) and has frequently been observed in alpine plant species (Pluess and Stöcklin 2004; Giménez-Benavides et al. 2007; Byars et al. 2009; GonzaloTurpin and Hazard 2009; Stöcklin et al. 2009; Frei et al. 2012). Moreover, strong phenotypic plasticity is likewise common in alpine species, and has been shown to provide a potential advantage for the persistence and survival of alpine species in a heterogeneous environment (Stöcklin et al. 2009; Frei et al. 2014). While the relative role of these two non-mutually exclusive strategies (i.e., adaptive genetic differentiation and plasticity), as well as the conditions for their evolution under divergent selection, are theoretically well understood, empirical evidence is rather scarce (Baythavong 2011; Hamann et al. 2016). The spatial grain size of environmental variation, defined by the degree of environmental variation as perceived by an individual plant across its dispersal distance, is likely to determine which of these mechanisms prevails (Alpert and Simms 2002; Pigliucci et al. 2003; Kawecki and Ebert 2004). Generally, adaptive genetic differentiation is expected when spatial grain size is coarse, whereas the evolution of phenotypic plasticity is expected when spatial grain size is fine (Baythavong 2011; Richardson et al. 2014). As such, local adaptation via genetic differentiation is more likely to occur when gene flow is limited between populations, as is the case in naturally fragmented landscapes or in populations separated by great geographic distances (Kawecki and Ebert 2004; Leimu and Fischer 2008). Alternatively, adaptive genetic differentiation is unlikely to evolve when gene flow among populations is extensive, and depending on the spatial grain size, the evolution of phenotypic plasticity may prevail (Kawecki and Ebert 2004). However, certain exceptions have been documented, such as adaptive genetic differentiation despite extensive gene flow, under strong micro-geographic divergent selection (Gonzalo-Turpin and Hazard 2009; Richardson et al. 2014).

Local adaptation is also contingent on other factors such as plant mating system, longevity, and clonality due to their effects on genetic diversity and the degree of genetic differentiation of populations (Galloway and Fenster 2000; Kawecki and Ebert 2004). Selfing, as opposed to outcrossing, reduces genetic diversity within populations, thereby compromising future adaptive potential (Linhart and Grant
1996). Similarly, clonality can limit the potential for local adaptation in case of limited sexual reproduction restricting genetic diversity within and among populations, but allows for plastic foraging among ramets (van Kleunen and Fischer 2001). Additionally, clonal plants may be less locally adapted currently if long-lived genets reflect adaptation to past conditions (Leimu and Fischer 2008; de Witte and Stöcklin 2010). Nevertheless, at high elevation, clonal reproduction is common amongst alpine species, and is associated with benefits such as the ability to forage for resources, support the establishment of offspring, and buffer against environmental variation (Billings and Mooney 1968).

Geum reptans L. (Rosaceae) is a long-lived clonal species occurring in high-alpine environments that reproduces sexually via strictly outcrossing flowers and vegetatively via clonal ramets on stolons. This species is an ideal system to study phenotypic variation and local adaptation, as it has been the subject of numerous prior investigations describing molecular and phenotypic variation, as well as gene flow among populations in the European Alps, and the relative importance of clonal vs. sexual reproduction (Pluess and Stöcklin 2004, 2005; Weppler et al. 2006; Stöcklin et al. 2009; Frei et al. 2012). Findings from Weppler et al. (2006) suggested that the role of sexual reproduction was not restricted to the maintenance of genetic variation or long-distance dispersal, but played an equally important role for population growth as reproduction via clonal offspring (Weppler et al. 2006). Moreover, prior studies showed that genetic diversity within populations is high despite clonality (Ellstrand and Elam 1993; Pluess and Stöcklin 2004) and natural habitat isolation (Stöcklin et al. 2009). Direct measures of gene flow via seeds and pollen indicated the maintenance of considerable gene flow over short distances and low molecular differentiation among close populations (Pluess and Stöcklin 2004). Furthermore, a glasshouse experiment revealed the great capacity of $G$. reptans to respond plastically to changes in environmental conditions, especially in its reproductive behavior (Pluess and Stöcklin 2005). Finally, a common garden experiment with $20 \mathrm{G}$. reptans populations spanning all biogeographic regions of the European Alps revealed that phenotypic differentiation reflected the glacial history of this species shaped by founder effects and past selection, but also suggested adaptation to current climate conditions (Frei et al. 2012). However, to rigorously prove that adaptation to local conditions has occurred, reciprocal transplantation experiments across original field sites are necessary (Kawecki and Ebert 2004), which have so far never been performed with this species.

Consequently, this study aimed at complementing previous ones, by investigating local adaptation via reciprocal transplantations of $G$. reptans populations growing at close 
or far geographical distances from each other in the Central Swiss Alps, and generally contributes to the body of empirical studies testing for local adaptation among alpine species. We investigated patterns of local adaptation in growth and reproductive traits by comparing the performance of sympatric and near- or far-allopatric site $\times$ population transplant combinations. We further measured leaf morphology traits known to be particularly plastic, yet not directly related to plant fitness (Frei et al. 2012), and investigated plastic responses to environmental site effects. For all traits, we quantified the importance of genetic vs. environmental variation (i.e., phenotypic plasticity), and leaf traits were further used to investigate potential selection for mean trait values at each site. In addition, we analyzed among and within population genetic diversity and molecular differentiation using microsatellite markers.

We specifically investigate (1) whether patterns of local adaptation are present amongst the studied populations of $G$. reptans (i.e., sympatric site $\times$ population transplant combinations outperform allopatric ones), (2) whether phenotypic plasticity is revealed in reproductive and leaf traits across sites, (3) if site-specific selection acts on leaf traits, and (4) whether genetic diversity within populations is maintained despite clonality and low molecular differentiation among close populations (i.e., because of gene flow over short distance).

\section{Materials and methods}

\section{Study species}

Geum reptans L. is a long-lived high-alpine species belonging to the Rosaceae family. It is widespread in the European Alps and extends eastward to the Carpathian mountains (Conert et al. 1995). The species occurs above $2100 \mathrm{~m}$ above sea level (a.s.l.) up to $3800 \mathrm{~m}$ a.s.l., and grows typically on moraines in glacier forelands, and on moist scree fields and mountain ridges (Aeschimann et al. 2004). Geum reptans is an early-successional species colonizing virgin soils after glacier retreat and usually persists until interspecific competition becomes too strong (Weppler et al. 2006). The species grows in rosettes with dissected compound leaves. The number of leaflet pairs on a leaf usually ranges from c. 5-15. Geum reptans can reproduce vegetatively by forming new rosettes (ramets) at the end of long stolons, but can also reproduce sexually via seeds borne on a single-flowered stem. Both reproductive strategies are not mutually exclusive and seem to contribute equally to population growth (Weppler et al. 2006). The yellow flowers are proterogynous, pollinated by insects and c. 100 seeds are produced per flower (Pluess and Stöcklin 2004). Seed dispersal spectra obtained from simulations showed that most seeds are dispersed across less than $10 \mathrm{~m}$, while long-distance seed dispersal over 100 and $1000 \mathrm{~m}$ can occur for 0.015 and $0.005 \%$ of seeds, respectively (Pluess and Stöcklin 2004; Tackenberg and Stöcklin 2008).

\section{Reciprocal transplantations}

Three large G. reptans populations were chosen for this reciprocal transplantation experiment growing at close or far distance from each other in the Central Swiss Alps (Table 1). For clarity, we will refer to the populations using italic font and to the sites using capital letters. Two populations, abbreviated as Flu growing at Flüelapass (FLU) and Dur growing at Dürrboden (DUR), were located at relatively close proximity from each other (c. $5 \mathrm{~km})$ near Davos (canton of Graubünden, Switzerland). A third population, abbreviated as Mut growing at Muttgletscher (MUT), was located at a larger geographic distance (c. $110 \mathrm{~km}$ from Davos) near the Furkapass (on the border between the canton of Uri and the canton of Valais, Switzerland). All three sites are glacier forelands but differed in elevation and exposition (Table 1). Soil temperature was recorded (as a proxy of smoothed air temperature; Körner and Paulsen 2004) during the second growing season (July-October 2015) using one data logger buried in the soil at a depth of $5 \mathrm{~cm}$ at each site (Thermochrome iButton Device Model DS1921G, Maxim Integrated Products, Inc., California, USA). Mean temperature differed among sites when averaged over the time of measurement (Table 1). Precipitation
Table 1 Location, geographic coordinates (latitude, longitude), elevation (m a.s.1.) and site characteristics of 3 Geum reptans populations sampled in the Central Swiss Alps. Pop, population abbreviation (in italic font); $n$, sample size of individuals used in the transplantations; Temp., mean temperature $\left({ }^{\circ} \mathrm{C}\right)$ averaged from July-October 2015 , indicative of the length of the growing season, measured with data loggers at each site; Prec., summed amount of precipitation (mm) from July-October 2015, as obtained from the nearest weather stations to our sites (Weissfluhjoch for FLU, Davos for DUR, Gütsch ob Anderatt for MUT, respectively; MeteoSwiss 2015); Exp., exposition of the slopes of the transplantation sites

\begin{tabular}{|c|c|c|c|c|c|c|c|}
\hline Location & Pop & Latitude & Longitude & Elevation & $n$ & Temp. & Prec. \\
\hline Flüelapass (FLU) & Flu & $46^{\circ} 44^{\prime} 54^{\prime \prime}$ & $9^{\circ} 56^{\prime} 54^{\prime \prime}$ & 2400 & 40 & 8.85 & 570 \\
\hline Dürrboden (DUR) & Dur & $46^{\circ} 42^{\prime} 29^{\prime \prime}$ & $9^{\circ} 56^{\prime} 12^{\prime \prime}$ & 2290 & 40 & 10.22 & 525 \\
\hline Muttgletscher (MUT) & Mut & $46^{\circ} 33^{\prime} 27^{\prime \prime}$ & $8^{\circ} 24^{\prime} 39^{\prime \prime}$ & 2480 & 40 & 7.39 & 465 \\
\hline
\end{tabular}


records, obtained for each site from nearby meteorological stations (MeteoSwiss 2015), also differed between sites when summed over the second growing season (July-October 2015; Table 1).

In September 2013, G. reptans populations were sampled from all three sites. For each population, 40 healthy mother plants were randomly chosen and three viable stolons with rosettes (ramets) were collected from each of these individuals. A minimum sampling distance of $5 \mathrm{~m}$ between mother plants was respected to minimize the risk of resampling genotypes (Pluess and Stöcklin 2004). Rosettes were kept in plastic bags and stored at $4{ }^{\circ} \mathrm{C}$ in the dark for a maximum of 2 days until they were planted in the greenhouse (Botanical Institute, Basel, Switzerland) in separate pots $7 \times 7 \times 8 \mathrm{~cm}$ filled with potting soil (Containererde, Ökohum GmbH, Herrenhof, Switzerland). Rosettes were grown for 9 months in the greenhouse, watered regularly to soil capacity, fertilized once a month (Wuxal, Syngenta Agro, Dielsdorf, Switzerland), and treated once with an insecticide (Spruzit ${ }^{\circledR}$, Neudorff $\mathrm{GmbH}$, Germany) to control infestations of Aphidoidae and Aleyrodidae. Four weeks before transplantation to field sites, plants were placed outdoors (Botanical Garden, Basel, Switzerland) for acclimation.

In July 2014, plants were reciprocally transplanted into field sites as soon as the snow had melted and the growing season had started. For each population, one ramet per genet was transplanted to each of the three sites. Each site thus received a total of 120 individuals, represented by 40 individuals per population ( 40 genets $\times 3$ populations). Due to the MUT site being far away from the two relatively nearby sites near Davos, transplantation resulted in 3 sympatric (i.e., populations transplanted back to their site of origin), 2 near-allopatric (i.e., populations transplanted to a site at close proximity), and 4 far-allopatric (i.e., populations transplanted to a site at far distance) site $\times$ population transplant combinations. Individuals were transplanted into the local soil, in a patch within the natural populations, and experienced local intra- and inter-specific competition, reflecting natural conditions. Tagged individuals were planted in rows of 10 , alternating between populations, with a minimal spacing of $20 \mathrm{~cm}$ between each other, and were watered once after planting to facilitate establishment.

Initial number of leaves was counted immediately after transplantation. After two growing seasons, in October 2015, we assessed whether plants had survived and reproduced. Number of leaves was counted on surviving individuals, and the number of flowers and/or stolons was counted for reproductive individuals. The total number of reproductive meristems was calculated for each individual by adding individual number of flowers and stolons. To assess the relative importance of clonal vs. sexual reproduction, we calculated the clonality of each individual as the proportion of stolons on all reproductive meristems. For each individual, we identified the longest leaf, measured its length and width, and counted the number of leaflets. As an indicator of its leaf shape, (i.e., also called leaf aspect ratio) we calculated the ratio between leaf length and leaf width. Degree of leaf dissection was estimated by dividing the number of leaflets by the leaf length. SLA was assessed for each individual by taking four circular corings of $5 \mathrm{~mm} \varnothing$ from different mature leaves (avoiding veins), drying them at $60^{\circ} \mathrm{C}$ for $48 \mathrm{~h}$ and weighing them together. SLA was then calculated as the fresh leaf area divided by the mean dry weight of the corings (Cornelissen et al. 2003). Aboveground dry mass was harvested and dried at $80^{\circ} \mathrm{C}$ for $72 \mathrm{~h}$ before weighing.

\section{Data analyses}

All traits were analyzed with generalized linear mixedeffect models (Crawley 2007), using Type III sum of squares with the lme4 (Bates et al. 2015) and lmerTest packages (Kuznetsova et al. 2013) for R. To test for local adaptation in survival, growth- and reproduction-related traits using the sympatric vs. allopatric contrast, we tested whether the means of the three (sympatric, near-allopatric and far-allopatric) distributions significantly differed from each other. To this end, we specified models including the factors site, population, and the contrast between sympatric, near- and far-allopatric transplant combinations (Blanquart et al. 2013). Local adaptation was considered to be operating if (1) the sympatric vs. allopatric contrast was significant, and if (2) sympatric transplant combinations outperformed allopatric ones (Blanquart et al. 2013). The replication of genets within populations was accounted for by including this factor in the models as a random factor. The initial number of leaves recorded at the time of transplantation was included in the model as a covariate to account for effects of initial plant size. This factor was, however, non-significant and therefore removed from the model for all traits except the final number of leaves.

For traits related to leaf morphology (i.e., leaf shape, leaf dissection and SLA), we analyzed if plastic responses were displayed in response to environmental conditions at field sites and if these responses differed between populations. To this end, we specified models testing for differences between sites and populations, the interaction between site and population, and included genets as a random factor in the model.

The proportion of surviving, reproductive (clonal and/ or sexual), and flowering individuals within each transplant combination (i.e., sympatric, near-allopatric, far-allopatric) was analyzed using a binomial distribution with a logit link function. The number of leaves, flowers, stolons, and total number of reproductive meristems were analyzed using a 
Poisson distribution with log link function (zero-inflated for the number of flowers, stolons, and total reproductive meristems). The remaining traits were assessed using a normal distribution with identity link function (Crawley 2007). To normalize data and homogenize variance aboveground dry mass was $\log$-transformed, count data $(\log +1)$-transformed, and ratios (clonality, leaf shape, leaf dissection, and SLA) arcsine-transformed (Crawley 2007). We report $p$ values after Bonferroni correction (i.e., $p$ values multiplied for nine response variables) and $F$-values (for fixed effects) or $\chi^{2}$-values (for random effects), the latter extracted with the "rand" function in lmerTest. Post hoc Tukey HSD multiple comparison tests were applied in the multcomp package (Hothorn et al. 2014) to detect significant differences among site $\times$ populations transplant combinations.

Variance components were calculated for all traits by fitting site, population, their interaction and genets as random factors. We extracted variances using the "VarCorr" function from the lme4 package (Crawley 2007).

Furthermore, as strong plastic effects were found in leaf traits, a follow-up selection analysis was performed to determine if environmental conditions at each field site selected for particular mean trait values. To do so, selection gradients were calculated by means of multiple linear regressions (Lande and Arnold 1983). Leaf shape, leaf dissection, and SLA site-specific trait values were standardized to a mean of zero and a variance of 1 prior to analysis. Relative fitness was calculated by dividing the number of reproductive meristems of each genet by the site-specific mean. Standardized linear (i.e., directional) selection gradients were estimated as the partial regression coefficient from the multiple regression of relative fitness on all standardized traits (Haggerty and Galloway 2011). We report selection gradients $\beta$ and $p$ values after Bonferroni correction (i.e., $p$ values multiplied for three response variables).

All the analyses were performed on $\mathrm{R}$ version 3.0.2 software (R Core Team 2013).

\section{Molecular analyses}

Leaf samples were taken randomly from 20 out of the 40 sampled mother plants of each population Flu, Dur, and Mut and immediately dried for DNA extraction using silica gel. Microsatellite marker development was performed by Ecogenics GmbH (Zurich-Schlieren, Switzerland), whose screening technique has previously been described in Kesselring et al. (2013). The 60 individuals were genotyped for nine microsatellite loci. A detailed description of microsatellite multiplex PCR in G. reptans can be found in Hamann et al. (2014). In brief, three multiplex PCRs were run. Multiplex I comprised primers for loci 015967, 011721, and 013998; multiplex II for loci 002235, 003651, and 011534, and multiplex III for loci 015615, 013198, and 007389. A fraction of the forward primers was fluorescent labeled with ATTO-dyes or FAM. Each multiplex PCR started with a denaturation step at $95^{\circ} \mathrm{C}$ for $15 \mathrm{~min}$, followed by 35 cycles of $94{ }^{\circ} \mathrm{C}$ for $30 \mathrm{~s}, 56^{\circ} \mathrm{C}$ for $90 \mathrm{~s}$, and $72^{\circ} \mathrm{C}$ for $60 \mathrm{~s}$, with a final extension step at $72{ }^{\circ} \mathrm{C}$ for $30 \mathrm{~min}$. Amplicons were loaded on an ABI3730 sequencer using an Eco500 size standard. Allele calling and crosschecking of genotypes were done with GeneMarker version 1.80 (SoftGenetics, State College, Pennsylvania, USA). Multiplex fingerprints in $G$. reptans have proven to be highly reproducible with an error rate of $1.4 \%$. Nonetheless, binning of a few alleles was performed (see Table 1 in Hamann et al. 2014). The final table of genotypes was exported to GenAlEx 6.5 (Peakall and Smouse 2006). GenAlex was used to check for identical multilocus genotypes among sampled individuals, and to estimate the genetic diversity within populations, calculated as the unbiased expected heterozygosity $\left(H_{\mathrm{e}}\right.$; Nei 1973). Additionally, the same software was used to perform an analysis of molecular variance (AMOVA) with 999 permutations to analyze partitioning of molecular variance among and within populations, and to calculate population pairwise $F_{\mathrm{ST}}$ values based on allele frequencies.

\section{Results}

\section{Proportion of surviving and reproducing plants}

On average, $85.8 \%$ of individuals survived from transplantation into field sites until harvest two growing seasons later. Survival was, however, independent of sympatric vs. near- and far-allopatric transplant combinations $(F=0.34, p=0.92)$. Of the surviving individuals, on average $40.6 \%$ of individuals reproduced during the second growing season via sexual and/or vegetative meristems, yet this proportion was also independent of sympatric $v s$. near- and far-allopatric transplant combinations $(F=0.11$, $p=0.69$ ). The frequency of individuals producing flowers was low with an average of only $17.5 \%$. Nevertheless, the proportion of individuals that flowered when transplanted to a distant site (i.e., far-allopatric) was lower compared to individuals transplanted back home or to a nearby site $(F=2.27, p=0.03)$. Indeed, only $14 \%$ of individuals flowered when grown in far-allopatric transplant combinations against 20 and $29 \%$ in sympatric and near-allopatric ones, respectively.

\section{Fitness-related growth and reproductive traits}

No significant differences were detected across the sympatric vs. allopatric contrast for any of the studied growth and reproductive traits (Table 2), suggesting that these 
Table 2 Results of generalized linear mixed-effect models for the responses in growth- (aboveground dry mass, number of leaves) and fitness-related traits (number of flowers, number of stolons, total number of reproductive structures, and clonality) in Geum reptans populations transplanted across field sites

\begin{tabular}{|c|c|c|c|c|c|c|c|c|c|c|c|c|c|c|c|c|c|c|}
\hline & \multicolumn{3}{|c|}{$\begin{array}{l}\text { Aboveground dry } \\
\text { mass }(\mathrm{g})\end{array}$} & \multicolumn{3}{|c|}{ Number of leaves } & \multicolumn{3}{|c|}{$\begin{array}{l}\text { Number of } \\
\text { flowers }\end{array}$} & \multicolumn{3}{|c|}{ Number of stolons } & \multicolumn{3}{|c|}{$\begin{array}{l}\text { Total reproductive } \\
\text { meristems }\end{array}$} & \multicolumn{3}{|c|}{ Clonality } \\
\hline & $D f$ & $F / \chi^{2}$ & $p$ & $D f$ & $F / \chi^{2}$ & $p$ & $D f$ & $F / \chi^{2}$ & $p$ & $D f$ & $F / \chi^{2}$ & $p$ & $D f$ & $F / \chi^{2}$ & $p$ & $D f$ & $F / \chi^{2}$ & $p$ \\
\hline Covariate & - & - & - & 1 & 189.04 & $<10^{-4}$ & - & - & - & - & - & - & - & - & - & - & - & - \\
\hline Site & 2 & 16.95 & $<10^{-4}$ & 2 & 39.80 & $<10^{-4}$ & 2 & 3.99 & 0.18 & 2 & 10.32 & $<10^{-4}$ & 2 & 12.15 & $<10^{-4}$ & 2 & 0.58 & 1 \\
\hline Population & 2 & 9.98 & $<10^{-4}$ & 2 & 0.29 & 1 & 2 & 1.26 & 1 & 2 & 8.64 & 0.0018 & 2 & 4.24 & 0.09 & 2 & 3.21 & 0.36 \\
\hline Symp vs. Allop & 2 & 0.93 & 1 & 1 & 0.90 & 1 & 1 & 1.78 & 1 & 1 & 0.46 & 1 & 1 & 0.05 & 1 & 1 & 0.92 & 1 \\
\hline Genets & 1 & 1.56 & 1 & 1 & 4.22 & 0.36 & 1 & 7.67 & 0.05 & 1 & 0.82 & 1 & 1 & 8.11 & 0.036 & 119 & 0.62 & 1 \\
\hline
\end{tabular}

$F$ - and $p$ values report the effects of site, population, the sympatric vs. allopatric contrast calculated as fixed factors. To account for the variation among genets within populations, this factor was included in the model as a random factor, for which $\chi^{2}$ - and $p$ values are reported. The covariate (i.e., number of initial leaves at time of transplantation) was significant only for number of leaves, and removed from models for the other traits. The $p$ values indicated in bold were significant after Bonferroni correction (at $\alpha=0.05 ; p$ values multiplied by 9 for correction), $p$ values in italics were significant before Bonferroni correction, and non-significant $p$ values were truncated at 1 if $>1$ after correction
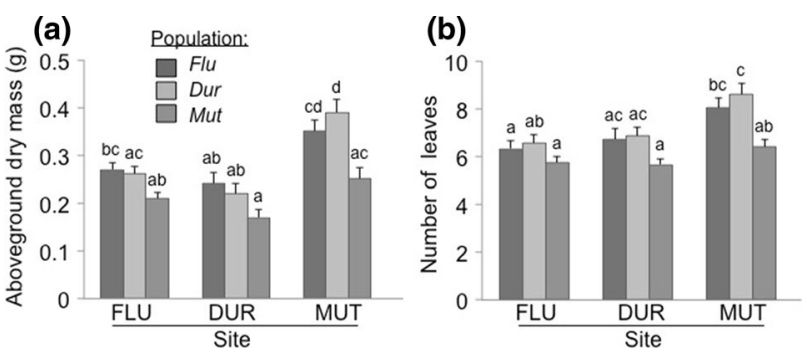

Fig. 1 Mean \pm SE of growth-related traits: aboveground dry mass (a) and number of leaves (b) in Geum reptans populations (Flu, Dur, Mut) transplanted across three sites (Flüelapass: FLU, Dürrboden: DUR, Muttgletscher: MUT). Letters reflect multiple contrast results (post hoc Tukey HSD test) between site $\times$ population transplant combinations

fitness-related traits did not differ between populations across transplant sites.

However, highly significant site effects were detected for all fitness-related traits, except for the number of flowers and clonality (Table 2). Similarly, population effects were strong for aboveground dry mass and the number of stolons $\left(F=9.98, p<10^{-4}, F=8.64, p=0.0018\right.$, respectively; Table 2). Site and population effects were pronounced for aboveground dry mass as population Dur grew best at the MUT site, even relative to the sympatric population Mut (Fig. 1a). Similarly, site effects were visible for the number of leaves, which was higher in population Flu and Dur when grown at the MUT site, relative to when grown at the FLU site (Fig. 1b). The number of flowers differed between genets $(F=7.67, p=0.05$; Table 2), and while the number of flowers produced by population Flu and Dur tended to be lower when grown at the far-away MUT site (Fig. 2a), this site effect was not significant after Bonferroni correction (Table 2). The
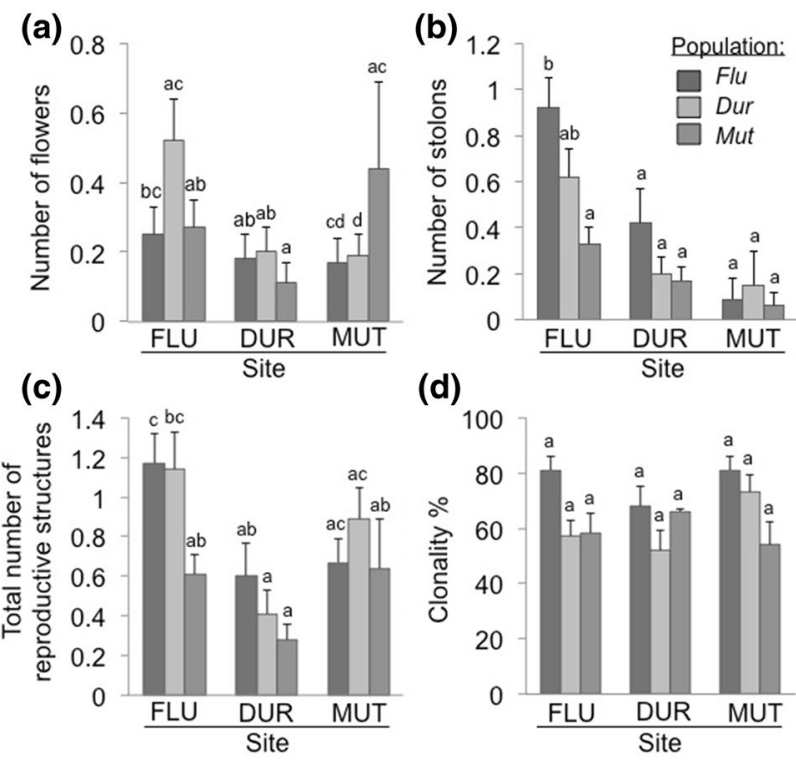

(d)

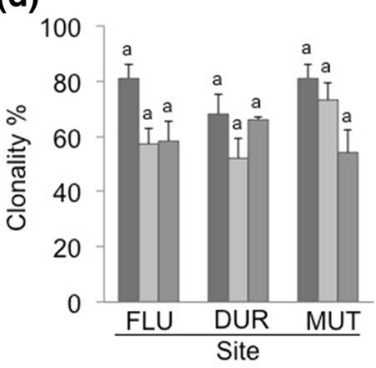

Fig. 2 Mean \pm SE of reproduction-related traits: number of flowers (a), number of stolons (b), the total number of reproductive meristems (c), and the clonality (d) in Geum reptans populations (Flu, Dur, Mut) transplanted across three sites (Flüelapass: FLU, Dürrboden: DUR, Muttgletscher: MUT). Letters illustrate multiple contrasts (post hoc Tukey HSD test) between site $\times$ population transplant combinations

number of stolons produced by individuals was particularly high in population Flu when grown at its site of origin (FLU), and relative to the population Mut when grown together at the FLU site (Fig. 2b). Similarly, site effects on the total number of reproductive meristems were pronounced for population Flu (Table 2), which produced a higher number of reproductive meristems when grown at its site of origin (FLU) relative to at the DUR site (Fig. 2c). Moreover, a genet effect was revealed 
for the total number of reproductive meristems $(F=8.11$, $p=0.036$; Table 2).

\section{Leaf morphology}

No significant interactions between site and population were detected for any of the traits related to leaf morphology (Table 3), indicating that populations did not differ in leaf morphology across transplant sites. However, highly significant site and/or population effects were detected for the leaf shape, leaf dissection, and SLA, and leaf dissection also differed across genets (Table 3 ).

Site and population effects in the leaf shape were particularly pronounced for population Mut grown at the FLU site, which had a higher leaf shape (i.e., smaller leaf width for a constant leaf length) than when grown at the DUR or MUT site (Fig. 3a), and in contrast to the two other populations at the FLU site (Fig. 3a). Similarly, site and population effects for leaf dissection were pronounced for population Flu, which had a higher leaf dissection ratio when grown at its site of origin (FLU) relative to when grown at the DUR site, and relative to population Mut when grown together at the FLU site (Fig. 3b). For SLA, the site effect was clearly visible when looking at population Dur, which displayed a significantly lower SLA when grown at its site of origin (DUR), relative to when grown at the FLU site (Fig. 3c).

\section{Partitioning of genetic and environmental effects}

For the growth-related traits, such as the aboveground dry mass and the number of leaves, environmental site effects explained about half of the trait variability (44.0 and $43.5 \%$, respectively; Table 4). However, genetic effects at the level of the population or of the genets explained the remaining portion of the variance in these traits (Table 4).

For the reproduction-related traits, genetic population or genet effects explained the main part of trait variation, but environmental site effects also explained roughly a quarter of the variability in the number of stolons and total reproductive meristems (Table 4). For the number of flowers and clonality, none of the variation resulted solely from environmental effects, but was mainly explained by genet effects (Table 4).

Finally, for two of the three studied traits indicative of leaf morphology, environmental effects and genetic effects determined trait variations at a similar proportion. Environmental site effects explained $50.1 \%$ of variation in leaf shape, and $37.3 \%$ in SLA. However, the variation in leaf dissection was mostly determined by genetic effects (27.6\% population, $49.9 \%$ genet; Table 4 ).
Table 3 Results of generalized linear mixed-effect models for the responses in the leaf shape, leaf dissection, and SLA in Geum reptans populations transplanted between field sites
Fig. 3 Mean \pm SE of leaf morphology traits: leaf shape (a), leaf dissection (b), and specific leaf area (c) in Geum reptans populations (Flu, Dur, Mut) transplanted across three sites (Flüelapass: FLU, Dürrboden: DUR, Muttgletscher: MUT). Letters illustrate multiple contrasts (post hoc Tukey HSD test) between site $\times$ population transplant combinations

\begin{tabular}{|c|c|c|c|c|c|c|c|c|c|}
\hline & \multicolumn{3}{|c|}{ Leaf shape } & \multicolumn{3}{|c|}{ Leaf dissection } & \multicolumn{3}{|c|}{ SLA } \\
\hline & $D f$ & $F / \chi^{2}$ & $p$ & $D f$ & $F / \chi^{2}$ & $p$ & $D f$ & $F / \chi^{2}$ & $p$ \\
\hline Site & 2 & 12.71 & $<10^{-4}$ & 2 & 10.90 & $<10^{-4}$ & 2 & 11.64 & $<10^{-4}$ \\
\hline Population & 2 & 8.91 & 0.0009 & 2 & 13.01 & $<10^{-4}$ & 2 & 4.71 & 0.081 \\
\hline Site $\times$ population & 4 & 1.49 & 1 & 4 & 0.49 & 1 & 4 & 1.86 & 1 \\
\hline Genets & 1 & 0.97 & 1 & 1 & 14.4 & 0.0018 & 1 & 1.62 & 1 \\
\hline
\end{tabular}

$F$ - and $p$ values report the effects of site, population, and the site $\times$ population interaction calculated as fixed factors. To account for the replication of genets within populations, this factor was included in the model as a random factor, for which $\chi^{2}$ - and $p$ values are reported. The $p$ values indicated in bold were significant after Bonferroni correction (at $\alpha=0.05 ; p$ values multiplied by 9 for correction), $p$ values in italics were significant before Bonferroni correction, and non-significant $p$ values were truncated at 1 if $>1$ after correction
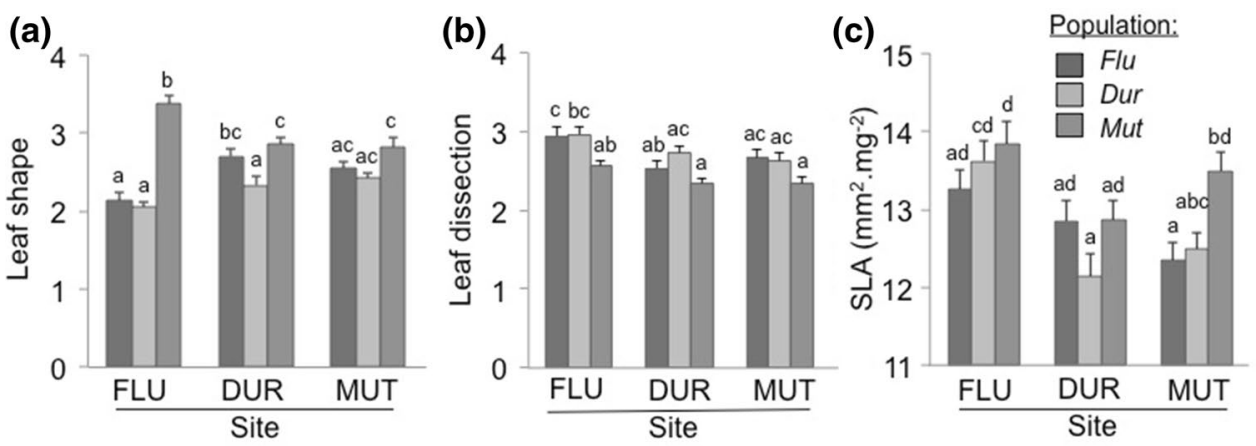
Table 4 Variance components (\%) of genetic effects (Population and Genets), environmental effects (Site) and interactive genotype $\times$ environment effects (Site $\times$ Pop) extracted for all fitness-related traits (growth and reproduction) and leaf morphology traits from three Geum reptans populations transplanted across three sites in the Central Swiss Alps

\begin{tabular}{lllll}
\hline & Site & Population & Site $\times$ pop & Genets \\
\hline $\begin{array}{lllll}\text { Growth-related traits } \\
\quad\end{array}$ & & & & \\
Aboveground dry mass & 43.99 & 22.98 & 3.18 & 29.84 \\
$\quad$ Number of leaves & 43.54 & 34.60 & 0.085 & 21.75 \\
$\begin{array}{l}\text { Reproduction-related traits } \\
\quad\end{array}$ & & & & \\
$\quad$ Number of flowers & 0 & 0 & 9.1 & 90.9 \\
$\quad$ Number of stolons & 26.63 & 36.13 & 9.27 & 27.97 \\
$\quad$ Total reproductive mer- & 23.68 & 9.46 & 1.50 & 65.36 \\
$\quad$ istems & & & & \\
$\quad$ Clonality & 0 & 31.62 & 0 & 68.38 \\
Leaf morphology & & & & \\
$\quad$ Leaf shape & 50.11 & 32.76 & 0 & 17.13 \\
$\quad$ Leaf dissection & 22.45 & 27.63 & 0 & 49.92 \\
SLA & 37.31 & 11.92 & 10.15 & 40.62 \\
\hline
\end{tabular}

\section{Site-specific selection on trait values}

Traits indicative of leaf morphology were found to be highly variable among transplant sites (Tables 3, 4). Thus, a selection analysis was performed to identify if selection for specific trait values occurred within experimental field sites. Most selection gradients calculated for SLA, leaf dissection, and leaf shape at each site were found to be non-significant, suggesting no correlation between leaf morphology and individual fitness measured as total number of reproductive meristems (Table 5). Only the leaf shape was under direct linear selection at the MUT site where plants with a smaller ratio (i.e., wider leaves for constant leaf length) had a marginally higher fitness (non-significant after Bonferroni correction: $\beta=-0.45, p=0.12$; Table 5).

\section{Molecular differentiation}

No identical multilocus genotypes (clonal offspring) were found across the 60 analyzed plants. We detected a mean number of alleles per population and locus of $7.18 \pm 0.49$, with a range of 3-11 alleles per locus. The mean genetic diversity (estimated as the unbiased expected heterozygosity) across all studied populations and loci was $H_{\mathrm{e}}=0.72 \pm 0.02$. The genetic diversity within populations ranged from 0.69 to 0.74 and did not significantly differ among populations. Low inbreeding was revealed by $F_{\text {IS }}=0.16 \pm 0.08$ across all populations and loci. AMOVA revealed that $11 \%$ of molecular variance was found among populations ( $p=0.001$; Table 6$)$, and $89 \%$ within populations (Table 6). Population pairwise $F_{\text {ST }}$ values suggest that little molecular differentiation resided between the two close populations near Davos (Flu and Dur; $\left.F_{\mathrm{ST}}=0.016\right)$. However, higher $F_{\mathrm{ST}}$ values were found when comparing populations Flu and Dur to Mut, the more distant population at Muttgletscher $\left(F_{\mathrm{ST}}=0.068\right.$ and $F_{\mathrm{ST}}=0.073$, respectively), suggesting higher molecular differentiation among distant populations.

Table 5 Standardized linear selection gradients $(\beta)$ and their level of significance ( $p$ value) estimated as the multiple regression coefficients of relative fitness (i.e., total number of reproductive meristems) on standardized mean trait values at each field site

\begin{tabular}{|c|c|c|c|c|c|c|}
\hline & \multicolumn{2}{|c|}{ Flüelapass (FLU) } & \multicolumn{2}{|c|}{ Dürrboden (DUR) } & \multicolumn{2}{|c|}{ Muttgletscher (MUT) } \\
\hline & $\beta$ & $p$ & $\beta$ & $p$ & $\beta$ & $p$ \\
\hline Leaf shape & -0.151 & 1 & -0.173 & 0.39 & -0.45 & 0.12 \\
\hline Leaf dissection & -0.148 & 1 & -0.031 & 1 & -0.083 & 1 \\
\hline SLA & 0.359 & 1 & 0.011 & 1 & -0.048 & 1 \\
\hline
\end{tabular}

The $p$ value in italics was significant before Bonferroni correction (at $\alpha=0.05 ; p$ values multiplied by 3 for correction), and non-significant $p$ values were truncated at 1 if $>1$ after correction

Table 6 AMOVA results showing the molecular variance among and within populations

\begin{tabular}{lrrllrl}
\hline Source & df & \multicolumn{1}{c}{ SS } & MS & Est. Var. & $\%$ & $p$ \\
\hline Among populations & 2 & 56.70 & 28.35 & 1.01 & 11 & 0.001 \\
Within populations & 57 & 460.10 & 8.07 & 8.07 & 89 & - \\
Total & 59 & 516.80 & - & 9.08 & 100 & - \\
\hline
\end{tabular}




\section{Discussion}

\section{Molecular differentiation and gene flow among populations}

High genetic diversity was found within the three populations $\left(H_{\mathrm{e}}=0.72\right)$. Our sampling method was designed in order to avoid picking the same genetic individual twice, by implementing at least 5 -m distance between sampled individuals. This method was apparently successful since no identical multilocus genotypes were found, which also suggests that clonal ramets of $G$. reptans establish predominantly at close proximity to their mother plants (Pluess and Stöcklin 2004; Hamann et al. 2014). Furthermore, this result suggests that the clonality of $G$. reptans did not cause a loss of genotypic diversity within populations, and is in line with previous findings reported in Pluess and Stöcklin (2004), and ultimately corroborates the consensus that populations of clonal species are often as genetically diverse as populations of non-clonal plants (Ellstrand and Elam 1993; Widen et al. 1994). While sexual reproduction probably plays an important role for recruitment during founding stages of a population after glacier retreat (Cannone et al. 2008) and for the preservation of genetic diversity (Weppler et al. 2006), the long lifespan of clonal ramets and potential immortality of genets undoubtedly contributes to the maintenance of genotypic diversity in G. reptans (de Witte et al. 2011).

Molecular differentiation was substantial among populations (11\%; Table 6). However, pairwise population $F_{\mathrm{ST}}$ comparisons revealed that molecular differentiation was low between the two populations growing at close proximity near Davos (Flu and Dur), yet both these populations differed strongly from the population Mut growing at a larger geographical distance at the MUT site. This suggests that gene flow is maintained over distances of c. $5 \mathrm{~km}$, despite the fact that these two populations are located in neighboring valleys, which is nonetheless in accordance with a prior studies on pollen and seed dispersal distances (Pluess and Stöcklin 2004; Tackenberg and Stöcklin 2008).

\section{Little evidence for local adaptation}

No differences were found in growth or reproductive traits between populations transplanted back to their home site or to foreign sites (i.e., sympatric vs. allopatric contrast). The frequency of individual survival and reproduction also did not differ across the sympatric vs. allopatric contrast, and only the frequency of flowering was lower in far-allopatric transplant combinations. Hence, our results suggest only little evidence for local adaptation in the studied G. reptans populations from the Central Swiss Alps, even when separated by relatively large geographic distances, where gene flow is probably restricted.

Evidence for local adaptation has been found in a number of alpine plant populations (Gonzalo-Turpin and Hazard 2009; Fischer et al. 2011; Giménez-Benavides et al. 2011; Hamann et al. 2016); however, an extensive meta-analysis and another recent study suggest that local adaptation may be less common than frequently assumed (Leimu and Fischer 2008; Hirst et al. 2016). Extensive gene flow among populations has been recognized as a main hindrance for local adaptation (Kawecki and Ebert 2004). Given the low level of molecular differentiation found in our study among populations at close proximity, this could potentially explain the lack of phenotypic differentiation between the two populations growing at the sites near Davos (FLU and DUR), but fails to do so for the more distant population at the MUT site. Nevertheless, the two nearby populations are c. $5 \mathrm{~km}$ apart, making genetic swamping very unlikely.

While it is possible that local adaptation may take more time than allowed in our experiment to express depending on plant longevity (Bennington et al. 2012; Hirst et al. 2016), the most likely explanation for the lack of local adaptation in our study is related to the narrow habitat niche of G. reptans. This species grows at high elevation, typically in glacier forelands, close to the glacier snout, and in moist scree fields (Aeschimann et al. 2004). Consequently, it is likely that environmental conditions are very similar in these habitats, regardless of geographic distance, which may explain the lack of intraspecific differentiation (Cannone et al. 2008; Cheplick 2015). Indeed, differences in elevation, temperature, precipitation, and exposition recorded in our study (Table 1) might not be substantial enough to lead to divergent selection. Supporting this interpretation, the selection analysis for mean leaf traits at different sites showed only little direct linear selection on these traits (Table 5), corroborating the fact that there was no divergent selection across the studied sites. Since only three populations from the Central Swiss Alps were studied here, it is important to note that adaptive genetic differentiation may in fact be found across larger geographic ranges, and such genetic differentiation may well be in line with this species' glacial history and postglacial recolonization (Frei et al. 2012).

An alternative, not mutually exclusive, explanation for the lack of local adaptation in our study could be that highly plastic phenotypic responses to local environmental conditions may overcome the need for genetic differentiation among populations, especially in perennial herbs (Antonovics and Primack 1982; Bazzaz 1996; Cheplick 2015; Hirst et al. 2016). Indeed, our study revealed that $G$. reptans had a great capacity to respond plastically to environmental conditions (Tables 2,3), which can represent a means to maximize plant performance in heterogeneous 
environments (Alpert and Simms 2002; Stöcklin et al. 2009; Nicotra et al. 2010). This may be especially true when considering the relatively narrow range of environmental conditions in the glacier forelands studied here, which may be within the limits that plants can adjust to by means of plastic responses (Alpert and Simms 2002). However, future studies should investigate the adaptive value of trait plasticity in contrast to genetic differentiation in more detail and across the entire geographical and ecological range of G. reptans.

\section{Phenotypic differentiation: environmental vs. genetic effects.}

While populations transplanted back to their home sites did not outperform populations transplanted to foreign sites, our experiment revealed certain differences in site characteristics (Tables 2, 3). Especially plants grown at the MUT site had a higher aboveground dry mass and produced a greater number of leaves compared to when grown at the other sites (Fig. 1). Variations in these traits were generally strongly driven by environmental conditions (Table 4). While we mentioned earlier that environmental conditions in glacier forelands are relatively similar, they can differ in the time lapse since glacier retreat and hence in their successional stage (Cannone et al. 2008). Indeed, the MUT site, where glacier retreat started in the mid 1990s, is at an earlier successional stage than the two sites near Davos, where glacier retreat started in the late nineteenth century (Schweizerisches-Gletschermessnetz 2015). Hence, this site is still at an early-successional stage, and might allow for better growth of pioneer and early-successional species, such as $G$. reptans, relative to sites at a later-successional stage where interspecific competition increases (Cannone et al. 2008). Similarly, the number of stolons and of total reproductive meristems produced by individuals was lower at the DUR site (Fig. 3), where higher competition might have hindered optimal reproduction.

Leaf morphology also varied greatly in response to environmental conditions at transplant sites. Variation in SLA equally reflected environmental and genetic differences among genets, and variation in the leaf shape predominantly resulted from plastic responses to environmental site conditions (Table 4). All these traits can help optimize light capture and gas exchange (Wright et al. 2004; Poorter et al. 2009), and may have positive repercussions on plant fitness if rapidly adjustable across diverse environments.

While genetic population and genet effects explained a large part of phenotypic variation in reproductive traits (Table 4), the reproductive output of individuals also varied between transplantation sites (i.e., plasticity). The low frequency of flowering individuals, and the high relative proportion of reproduction via clonal ramets (Fig. 2d) were probably related to the young age and small size of our experimental plants as found in prior studies (Pluess and Stöcklin 2005; Weppler et al. 2006). Pluess and Stöcklin (2005) also revealed a great size-dependent plasticity in the reproductive strategy of G. reptans, which ensures population persistence and reproduction across a range of habitat conditions, and corroborates our hypothesis that phenotypic plasticity might prevail over genetic differentiation in G. reptans growing in glacier forelands in the Swiss Alps.

\section{Conclusion}

Our study revealed only little evidence for local adaptation of $G$. reptans populations growing on the studied glacier forelands in the Central Swiss Alps, even though extensive molecular differentiation was found between the far-away populations. We suggest that the niche of this species is relatively narrow, and restricted to similar environmental conditions in glacier forelands and moist screes. Moreover, both growth- and reproduction-related traits, as well as leaf traits exhibited strong phenotypic plasticity, which may overcome the need to adapt by means of genetic differentiation. Since only a limited number of populations were studied here, we cautiously advocate that selection could have led to the evolution of phenotypic plasticity rather than genetic differentiation, and encourage future studies to investigate the adaptive value of phenotypic plasticity across the natural range of this species.

Acknowledgements We thank the local authorities in the municipality of Davos, and the Alpine Research Station Furka ALPFOR at the Furkapass for allowing us to conduct the reciprocal transplantations. Acknowledgments also go out to Guy Villaume, Ayaka Gütlin, Diego Delgadillo, Sara Badel, Michael O'Connor, and Rémi Nguyen for their help in setting up the experiment and in the field. This work was supported by the Swiss National Science Foundation (project no. 3100 A-135611 to J.S) and by the Freiwilige Akademische Gesellschaft and the Basler Stiftung für Biologische Forschung to E.H.

\section{Compliance with ethical standards}

Conflict of interest Data and findings presented in this manuscript have not been published and are not under consideration for publication elsewhere. All the authors have approved this submission and all persons entitled to authorship have been named. The authors have no conflict of interest to declare.

Open Access This article is distributed under the terms of the Creative Commons Attribution 4.0 International License (http:// creativecommons.org/licenses/by/4.0/), which permits unrestricted use, distribution, and reproduction in any medium, provided you give appropriate credit to the original author(s) and the source, provide a link to the Creative Commons license, and indicate if changes were made. 


\section{References}

Aeschimann L, Lauber K et al (2004) Flora alpina. Haupt Verlag, Bern, pp 2670

Alpert P, Simms EL (2002) The relative advantages of plasticity and fixity in different environments: when is it good for a plant to adjust? Evol Ecol 16:285-297

Antonovics J, Primack RB (1982) Experimental ecological genetics in Plantago: VI. The demography of seedling transplants of $P$. lanceolata. J Ecol 70:55-75

Banta JA, Dole J et al (2007) Evidence of local adaptation to coarse-grained environmental variation in Arabidopsis thaliana. Evol Int J org Evol 61:2419-2432

Bates D, Meachler M et al (2015) Fitting linear mixed-effects models using lme4. J Stat Softw 67:1-48

Baythavong BS (2011) Linking the spatial scale of environmental variation and the evolution of phenotypic plasticity: selection favors adaptive plasticity in fine-grained environments. Am Nat 178:75-87

Bazzaz FA (1996) Plants in Changing Environments. Cambridge University Press, New York, pp 320

Bennington CC, Fetcher $\mathrm{N}$ et al (2012) Home site advantage in two long-lived arctic plant species: results from two 30-year reciprocal transplant studies. J Ecol 100:841-851

Billings WD, Mooney HA (1968) Ecology of arctic and alpine plants. Biol Rev Camb Philos Soc 43:481-529

Blanquart F, Kaltz O et al (2013) A practical guide to measuring local adaptation. Ecol Lett 16:1195-1205

Bradshaw AD (1984) Ecological significance of genetic variation between populations. In: Perspecitves on plant population ecology. Sinauer, Sunderland

Byars SG, Papst W et al (2007) Local adaptation and cogradient selection in the alpine plant, Poa hiemata, along a narrow altitudinal gradient. Evol Int J org Evol 61:2925-2941

Byars SG, Parsons Y et al (2009) Effect of altitude on the genetic structure of an Alpine grass, Poa hiemata. Ann Bot (Lond) 103:885-899

Cannone N, Diolaiuti G et al (2008) Accelerating climate change impacts on alpine glacier forefield ecosystems in the European Alps. Ecol Appl 18:637-648

Cheplick GP (2015) Approaches to plant evolutionary ecology. Oxford University Press, New York, p 291

Conert HJ, Jäger EJ et al (1995) Illustrierte Flora von Mitteleuropa. Blackwell Scientific Publications, Berlin, p 504

Cornelissen JHC, Lavorel S et al (2003) A handbook of protocols for standardised and easy measurement of plant functional traits worldwide. Aust J Bot 51:335-380

Crawley MJ (2007) The R Book. Wiley, West Sussex, p 949

de Witte LC, Stöcklin J (2010) Longevity of clonal plants: why it matters and how to measure it. Ann Bot (Lond) 106:859-870

de Witte LC, Scherrer D et al (2011) Genet longevity and population age structure of the clonal pioneer species Geum reptans based on demographic field data and projection matrix modelling. Preslia 83:371-386

Ellstrand N, Elam D (1993) Patterns of genotypic diversity in clonal plant species. Am J Bot 74:123-131

Fischer M, Weyand A et al (2011) Adaptation of Poa alpina to altitude and land use in the Swiss Alps. Alpine Bot 121:91-105

Frei ES, Scheepens JF et al (2012) Phenotypic differentiation in a common garden reflects the phylogeography of a widespread Alpine plant. J Ecol 100:297-308

Frei ER, Ghazoul J et al (2014) Plastic responses to elevated temperature in low and high elevation populations of three grassland species. PLoS One 9
Galloway LF, Fenster CB (2000) Population differentiation in an annual legume: local adaptation. Evol Int $\mathbf{J}$ org Evol 54:1173-1181

Giménez-Benavides L, Escudero A et al (2007) Local adaptation enhances seedling recruitment along an altitudinal gradient in a high mountain Mediterranean Plant. Ann Bot (Lond) 99:723-734

Giménez-Benavides L, García-Camacho R et al (2011) Selection on flowering time in Mediterranean high-mountain plants under global warming. Evol Ecol 25:777-794

Gonzalo-Turpin H, Hazard L (2009) Local adaptation occurs along altitudinal gradient despite the existence of gene flow in the alpine plant species Festuca eskia. J Ecol 97:742-751

Haggerty BP, Galloway LF (2011) Response of individual components of reproductive phenology to growing season length in a monocarpic herb. J Ecol 99:242-253

Hamann E, Kesselring $\mathrm{H}$ et al (2014) Novel microsatellite markers for the high-alpine Geum reptans (Rosaceae). Appl Plant Sci 2:1400021

Hamann E, Kesselring $\mathrm{H}$ et al (2016) Evidence of local adaptation to fine- and coarse-grained environemntal variability in Poa alpina in the Swiss Alps. J Ecol 104:1627-1637

Hirst MJ, Sexton JP et al (2016) Extensive variation, but not local adaptation in an Australian alpine daisy. Ecol Evol 6:5459-5472

Hothorn T, Bretz F et al (2014) Simultaneous inference in general parametrics models. Biom J 50:346-363

Joshi J, Schmid B et al (2001) Local adaptation enhances performance of common plant species. Ecol Lett 4:536-544

Kawecki TJ, Ebert D (2004) Conceptual issues in local adaptation. Ecol Lett 7:1225-1241

Kesselring H, Hamann E et al (2013) New microsatellite markers for Anthyllis vulneraria (Fabaceae), analyzed with Spreadex gel electrophoresis. Appl Plant Sci 1:1300054

Körner C (2003) Alpine plant life: functional plant ecology of high mountain ecosystems. Springer Verlag, Germany, pp 350

Körner C, Paulsen J (2004) A world-wide study of high altitude treeline temperatures. J Biogeogr 31:713-732

Kuznetsova A, Brockhoff PB et al (2013) lmerTest: Tests for random and fixed effects for linear mixed effect models (lmer objects of lme4 package) http://cran.r-project.org/package=lmerTest.

Lande R, Arnold SJ (1983) The measurement of selection on correlated characters. Evol Int J org Evol 37:1210-1226

Leimu R, Fischer M (2008) A meta-analysis of local adaptation in plants. PLoS One 3(12):e4010. doi:10.1371/journal. pone. 0004010

Linhart YB, Grant MC (1996) Evolutionary significance of local genetic differentiation in plants. Annu Rev Ecol Syst 27:237-277

MeteoSwiss (2015) Federal Office of Meteorology and Climatology. http://www.meteoswiss.admin.ch (12.11.2015)

Nei M (1973) Analysis of gene diversity in subdivided populations. Proc Natl Acad Sci 70:3321-3323

Nicotra AB, Atkin OK et al (2010) Plant phenotypic plasticity in a changing climate. Trends Plant Sci 15:684-692

Peakall R, Smouse PE (2006) GENALEX 6: genetic analysis in Excel. Population genetic software for teaching and research. Mol Ecol Notes 6:288-295

Pigliucci M, Pollard H et al (2003) Comparative studies of evolutionary responses to light environments in Arabidopsis. Am Nat $161: 68-82$

Pluess AR, Stöcklin J (2004) Population genetic diversity of the clonal plant Geum reptans (Rosaceae) in the Swiss Alps. Am J Bot 91:2013-2021

Pluess AR, Stöcklin J (2005) The importance of population origin and environment on clonal and sexual reproduction in the alpine plant Geum reptans. Funct Ecol 19:228-237 
Poorter H, Niinemets U et al (2009) Causes and consequences of variation in leaf mass per area (LMA): a meta-analysis. New Phytol 182:565-588

R Core Team (2013) R: A language and environment for statistical computing. R Foundation for statistical computing, Vienna, http://www.R-project.org/

Richardson JL, Urban MC et al (2014) Microgeographic adaptation and the spatial scale of evolution. Trends Ecol Evol 165-176

Scherrer D, Körner C (2011) Topographically controlled thermal-habitat differentiation buffers alpine plant diversity against climate warming. J Biogeogr 38:406-416

Schweizerisches-Gletschermessnetz (2015) Gletscherberichte (18812014). "Die Gletscher der Schweizer Alpen", Jahrbücher der Expertenkommision für Kryosphärenmessnetze der Akademie der naturwissenschaften Schweiz (SCNAT). ETH Zürich: Versuchsanstalt für Wasserbau, Hydrologie und Glaziologie (VAW)

Stöcklin J, Kuss P et al (2009) Genetic diversity, phenotypic variation and local adaptation in the alpine landscape: case studies with alpine plant species. Bot Helv 119:125-133
Sultan SE (1995) Phenotypic plasticity and plant adaptation. Acta Botanica Neerlandica 44:363-383

Tackenberg O, Stöcklin J (2008) Wind dispersal of alpine plant species: a comparison with lowland species. J Veg Sci 19:109-118

van Kleunen M, Fischer M (2001) Adaptive evolution of plastic foraging responses in a clonal plants. Ecology 82:3309-3319

Volis S, Ormanbekova D et al (2015) Multi-approaches analysis reveals local adaptation in the Emmer Wheat (Triticum dicoccoides) at macro- but not micro-geographical scale. PLoS One 10:e0121153

Weppler T, Stoll P et al (2006) The relative importance of sexual and clonal reproduction for population growth in the long-lived alpine plant Geum reptans. J Ecol 94:869-879

Widen B, Cronberg N et al (1994) Genotypic diversity, molecular markers, and spatial distribution of genets in clonal plants, a literature survey. Folia Geobotanica et Phytotaxonomica 29:245-263

Wright IJ, Reich PB et al (2004) The worldwide leaf economics spectrum. Nature 428:821-827 